\section{P3.070 RISK FACTORS AND PREVALENCE OF CHLAMYDIA AND GONORRHOEA IN PUBLIC HEALTH SEXUAL HEALTH CLINICS IN HAMILTON, ON}

doi:10.1136/sextrans-2013-051184.0530

${ }^{1}$ G Hovhannisyan, ${ }^{2} \mathrm{C}$ Lee, ${ }^{3} \mathrm{~S}$ Hogg-Johnson, ${ }^{4} \mathrm{~S}$ Bondy, ${ }^{4} \mathrm{M}$ Millson. ${ }^{1} \mathrm{Mc}$ Master University, Hamilton, ON, Canada; ${ }^{2}$ Public Health Ontario, Toronto, ON, Canada; ${ }^{3}$ nstitute for Work and Health, Toronto, ON, Canada; ${ }^{4}$ University of Toronto, Toronto, ON, Canada

Background Chlamydia and gonorrhoea are the most common bacterial sexually transmitted infections (STIs) in Canada. However, the prevalence of these STIs, as well as the risk profile of clients attending public health sexual health $(\mathrm{SH})$ clinics, have not been well characterised in Canada.

Methods Female clients of Hamilton Public Health SH clinics between Jan 2009 and Dec 2011 were enrolled in the study. Retrospective chart review was conducted. Logistic regression was conducted to identify important risk factors for STIs in predicting gonococcal and chlamydial infections.

Results 2694 charts were abstracted from Hamilton Public Health $\mathrm{SH}$ clinics. The mean age of the clients was 24 years; $50 \%$ of the clients were under 21 years of age. The majority of the clients were sexually active (98\%), of whom $147(6 \%)$ had both male and female partners, 27(1\%) had only female partners, and 2405 (92\%) had only male partners. Most clients practised vaginal (96.6\%) and oral sex (74\%). Anal sex, oral-anal sex and shared sex toys were less common with $12 \%, 2.2 \%$ and $2 \%$ of clients reporting these practises, respectively. Over half of the clients reported having more than 1 partner in the past year, $36 \%$ of clients reported two or three partners and $15 \%$ reported having four or more partners in the past year. The proportion of clients who had at least one test for gonorrhoea and chlamydia during the study period was $58 \%$. The overall prevalence of chlamydia and gonorrhoea were $8 \%$ and $1 \%$, respectively. The strongest predictor of these STIs was young age: ORs were 3.4 and 4.2 for age groups $<20$ and $20-24$ compared to $>30$ years old.

Conclusion The prevalence of chlamydia and gonorrhoea was considerably higher in clients attending $\mathrm{SH}$ clinics in Hamilton compared to population and family practise based estimates. Age remains the strongest predictor of these infections.

\section{P3.071 OVERUTILIZATION OF CHLAMYDIA AND GONORRHEA TESTS IN OLDER WOMEN}

doi:10.1136/sextrans-2013-051184.0531

'J A Jackson, ' J Coleman, ${ }^{2}$ E Ludwig. 'Johns Hopkins University School of Medicine, Baltimore, MD, United States; '2Johns Hopkins University, Baltimore, MD, United States

Background Baltimore City ranks in the top half among major US cities for rates of chlamydia infections, $80 \%$ of which were from women $<26$ years of age. Research has shown that younger women who are at the highest risk for chlamydia are being undertested while older women are being overtested. The purpose of this study was to determine the prevalence of chlamydia and gonorrhoea (CT and GC) infections in women $\geq 26$ who are at increased risk of infection and to determine factors associated with a positive test.

Methods We conducted a retrospective chart review of medical records for all Medicaid-insured women aged 26 and older who were seen for a gynaecology visit at an academic medical institution in Baltimore, MD from January 2009 to December 2010 and tested for CT and GC. Pregnant women and those who were HIV positive were excluded from the study.

Results Of the 625 women that were included in the study, the median age of those testing positive for CT or GC was 30 (IOR 28-32). For those who tested negative, the median age was 35 (IOR $30-45)$. No woman over the age of 45 had a positive test. The prevalence of CT and GC in this population was $1.7 \%$ and $0.3 \%$, respectively. By only testing women who were symptomatic, had a history of an STI, who complained of being exposed to an STI, or were 40 years or younger, we captured all positive tests and screened $86.4 \%$ of the original 625 patients.

Conclusion There remains a low prevalence of chlamydia and gonorrhoea in older women, regardless of risk factors. We recommend selective screening of high-risk women (STI exposure, symptomatic, or hx of STI). This research demonstrates the need for improved adherence to and rethinking of CT and GC guidelines in older women.

\section{P3.072 STI CO-INFECTIONS WITHOUT ANY SYMPTOMS? - SCREENING IS NECESSARY}

doi:10.1136/sextrans-2013-051184.0532

N Mihalik, K Pónyai, B Tóth, É Nemes-Nikodém, E Ostorházi, M Marschalkó, S Kárpáti. Department of Dermatology, Venerology and Dermatooncology, Budapest, Hungary

Background Sexually transmitted infections (STI) are not always smptomatic. Undetected and untreated STIs of the genital tract may result in long-term sequelae, such as pelvic inflammatory disease, infertility and ectopic pregnancy. Our aim was to determine the prevalence of 7 different STI pathogens and the prevalence of possible coinfections in symptomfree men and women using PCR technique.

Methods A total of 51 specimens, including vaginal $(n=19)$ and urethral $(\mathrm{n}=32)$ swabs were collected from asymptomatic patients attended to the hungarian National STD Center. Samples were obtained and tested for Ureaplasma parvum, Ureaplasma urealyticum, Mycoplasma genitalium, Mycoplasma hominis, Neisseria gonorrhoeae, Chlamydia trachomatis and Trichomonas vaginalis by PCR examination (AnyplexTM II STI-7 Detection, Seegene).

Results During the study period 19/51 genito-urethral samples (11/19 female, 8/19 male samples) containing at least one genitourethral pathogen were detected. The mean age of the patients was 40 years. $16 / 19$ patients had infection caused by a single pathogen. The most frequent pathogens belonged to the Ureaplasmataceae family (15/19: 10 female, 5 male): Ureaplasma parvum (12/15) was more prevalent than Ureaplasma urealyticum (3/15). Mycoplasma genitalium occured only in one sample in this population. 3/19 patients had co-infection without any symptoms: Ureaplasma species were coupled with Mycoplasma hominis two times and once with Neisseria gonorrhoeae in these cases. Chlamydia trachomatis and Trichomonas vaginalis were not detected in the samples during screening

Conclusion Females carry STI pathogens more commonly than males. High prevalence of Ureaplasma sp. in symptomfree female patients suggests that women, especially before conception, should be screened for more STI pathogens not only for N. gonorrhoeae or C. trachomatis. Occurence of co-infections is also possible in the asymptomatic population.

\section{P3.073 PERFORMANCE OF SELF-COLLECTED VAGINAL SWABS IN DIAGNOSIS OF BACTERIAL VAGINOSIS AMONG YOUNG REPRODUCTIVE AGE WOMEN IN MYSORE, INDIA}

doi:10.1136/sextrans-2013-051184.0533

${ }^{1}$ V Srinivas, ${ }^{1} \mathrm{~K}$ Ravi, ${ }^{1} \mathrm{~A}$ Arun, 'B Niranjankumar, ${ }^{1} \mathrm{R}$ Shaheen, ${ }^{1} \mathrm{P}$ Jaykrishna, ${ }^{2} \mathrm{~K}$ Krupp, 2P Madhivanan. 'Public Health Research Institute of India, Mysore, India; ${ }^{2}$ Public Health Research Institute of India, Robert Stempel College of Public Health, Florida International University, Miami, FL, United States

Background Culturally, women are less inclined to undergo a perspeculum examination for screening of reproductive tract infections and consider self-sampling more acceptable. This study examines the concordance between Gram stains of vaginal smears and $\mathrm{pH}$ obtained by clinician conducted speculum examination with similar smears and $\mathrm{pH}$ prepared from self-collected vaginal swabs. 